\title{
Production of a Fluorescence Resonance Energy Transfer (FRET) Biosensor Membrane for MicroRNA Detection
}

Received 00th January 20xx, Accepted 00th January 20xx DOI: $10.1039 / \times 0 \times x 00000 x$

www.rsc.org/

\author{
Yike Fua, Tong Chen ${ }^{a}$, Tongxu Guª ${ }^{a}$ Yuxi Xie ${ }^{a}$, Yu Luo ${ }^{a}$, Gang Wang ${ }^{a}$, Congkun Xie ${ }^{a}$, Jie Huang ${ }^{b}$, Xiang \\ $\mathrm{Li}^{\mathrm{a} *}$, Serena Best ${ }^{\mathrm{c}}$, Gaorong Han ${ }^{\mathrm{a} *}$
}

\begin{abstract}
MicroRNAs (miRNAs) play a key role in regulating gene expression but can be associated with abnormalities linked to carcinogenesis and tumor progression. Hence there is increasing interest in developing methods to detect these noncoding RNA molecules in the human circulation system. Here, a novel FRET miRNA-195 targeting biosensor, based on silica nanofibers incorporated with rare earth-doped calcium fluoride particles $\left(\mathrm{CaF}_{2}: \mathrm{Yb}, \mathrm{Ho} @ \mathrm{SiO}_{2}\right)$ and gold nanoparticles (AuNPs), is reported. The formation of a sandwich structure, as a result of co-hybridization of the target miRNA which is captured by oligonucleotides conjugated at the surface of $\mathrm{CaF}_{2}: \mathrm{Yb}, \mathrm{Ho} @ \mathrm{SiO}_{2}$ fibers and AuNPs, brings the nanofibers and AuNPs into close proximity and triggers the FRET effect. The intensity ratio of green to red emission, $I_{541} / I_{650}$, was found to decrease linearly with increasing concentration of the target miRNA and this can be utilized as a standard curve for quantitative determination of miRNA concentration. This assay offers a simple and convenient method for miRNA quantification, with the potential for rapid and early clinical diagnosis of diseases such as breast cancer.
\end{abstract}

\section{Introduction}

There is increasing concern about the very high numbers of breast cancer-related deaths worldwide. In 2012, there were more than 1.7 million diagnosed cases, 521,900 deaths and overall, the disease represents $15 \%$ of cancer deaths in the female population. ${ }^{1}$ Hence, there is an urgent need for the development of early detection methodologies to expand and inform treatment options and offer the potential for improved clinical outcome.

MicroRNAs (miRNAs), a class of small noncoding RNA molecules ( 22 nucleotides in length), are thought to be involved in the regulation of $\sim 30 \%$ of human genes and to play a role in a range of biological processes including, the cell cycle, differentiation and metabolism. ${ }^{2-5}$ They are also believed to be associated with human diseases such as diabetes, neurodegenerative or immuno- disorders and cancer. ${ }^{5}$ The de-regulation or dysfunction of miRNAs plays an important role in carcinogenesis and disease progression. Since the existence of miRNAs in the circulatory system was confirmed, the expression profile of serum miRNAs has emerged as a promising

\footnotetext{
a. State Key Laboratory of Silicon Materials, School of Materials Science and Engineering, Zhejiang University, Hangzhou, Zhejiang 310027, P. R. China.

b. Department of Mechanical Engineering, University College London, London WC1E 7JE, UK.

c. Department of Materials Science and Metallurgy, University of Cambridge, Cambridge CB3 OFS, UK.

*E-mail:xiang.li@zju.edu.cn; hgr@zju.edu.cn

Electronic Supplementary Information (ESI) available: Diameter distribution of $\mathrm{CaF}_{2}: \mathrm{Yb}$, Ho nanoparticles hydrothermally at $180{ }^{\circ} \mathrm{C}$ for $24 \mathrm{~h}$. SEM and TEM of $\mathrm{CaF}_{2}: \mathrm{Yb}$, Ho nanoparticles calcined at $700{ }^{\circ} \mathrm{C}$ for $4 \mathrm{~h}$. Simplified energy level scheme of $\mathrm{Yb}^{3+} / \mathrm{Ho}^{3+}$ ions with mechanisms of energy transfer under excitation of $980 \mathrm{~nm}$ NIR. UV-vis absorption of $\mathrm{CaF}_{2}: \mathrm{Yb}, \mathrm{Ho} @ \mathrm{SiO}_{2}-\mathrm{NH}_{2}$, Probe 1 and $\mathrm{CaF}_{2}: \mathrm{Yb}, \mathrm{Ho} @ \mathrm{SiO}_{2}$ Probe 1 conjugation. See DOI: 10.1039/x0xx00000x
}

and convenient diagnostic bio-marker for non-invasive, early-stage disease detection. ${ }^{6,7}$ MiRNA-195 (miR-195) has been shown to play an important role in breast tumorigenesis. ${ }^{8}$ For example, bloodbased miRNA profiling studies demonstrated that systemic miR-195 levels were raised in breast cancer patients, but decreased after surgery. ${ }^{9}, 10$ Thus, rapid and efficient detection of miR-195 is essential for early diagnosis of breast cancer.

However, the detection of miRNAs in clinical samples is challenging due to their short sequences, single base differences and extremely low concentration. ${ }^{11,12}$ Various sensing mechanisms have been developed for miRNA measurement, including electrochemical and electromechanical biosensing and surface plasmon resonance..$^{13-15}$

Fluorescence resonance energy transfer (FRET), in which the electronic excitation energy of an energy donor chromophore is transferred to an energy acceptor in the presence of a target, has been used previously in miRNA detection. ${ }^{16-18}$ Traditional fluorophores used in FRET-based detection include Cy5, FAM and Texas red. However, these are limited by intrinsic drawbacks including broad emission bands and photobleaching effects. ${ }^{19}$

To address these issues, alternative methods have been explored, such as those based on upconversion photoluminescent (UCPL) nanomaterials. These materials offer the advantages of high quantum yields, narrow emission peaks, long lifetimes, superior photostability, deep penetration and low toxicity. ${ }^{20-24}$ More importantly, upconversion is a process where low-energy light, (usually near-infrared (NIR) or infrared (IR)) is converted to higherenergy light (UV or visible), through multiple photon absorptions or energy transfers. This property does not occur in natural biological materials. ${ }^{25,} 26$ Therefore, there is no background auto-fluorescence 
from biological systems, which means that the signal-to-noise ratio and sensitivity of the detection is high. ${ }^{27}$ These advantages have made UCPL materials an ideal choice as the fluorescence donor in FRET-based biological detection.

Fluoride materials (such as $\mathrm{NaYF}_{4}$ ) have been investigated extensively as matrices for rare earth doping ${ }^{28-30}$ and, in particular, the unique NIR-to-visible UCPL properties and low phonon energies of $\mathrm{CaF}_{2}$ nanomaterials offer the potential to minimize multiphonon de-excitation. In addition, when these materials are doped with rare earth elements, the energy transfer rate can be accelerated due to charge compensation effects, the promotion of pair formation and the influence on lattice structure - all of which enhance the probability of UC. ${ }^{31}, 32$ However, despite these advantages, there appears to have been little work on the use of rare earth-doped $\mathrm{CaF}_{2}$ in FRET-based technology for the detection of biomolecules such as miRNA. To date reports have focused on the production of $\mathrm{CaF}_{2}: \mathrm{Yb}$, Ho for optical applications ${ }^{33}$ and the use of $\mathrm{CaF}_{2}: \mathrm{Ce}, \mathrm{Tb}$ in avidin and uPAR detection in particulate form ${ }^{34}$.

Gold nanoparticles (AuNPs) have been used extensively to quench fluorescence signals. They have also been used in gene delivery applications $\mathrm{s}^{35-37}$, and have been used to detect immunoglobulin $\mathrm{G}$ and ss-DNA ${ }^{38,39}$, but there does not appear to have been work reported on the detection of miRNA-195 sequences.

In a FRET-based detection system, it is necessary to ensure a spectral overlap between the emission of the donor and the absorption of acceptor. The absorption of gold nanoparticles with a diameter of $10-20 \mathrm{~nm}$ is usually located in the green region. ${ }^{19,} 40$ Therefore, strong green emission from the energy donor is essential for FRET effects, in order to optimise the sensitivity.

Photoluminescent $\mathrm{CaF}_{2}: \mathrm{Yb}, \mathrm{Er}$ embedded in $\mathrm{SiO}_{2}$ nanofibers have been used in drug delivery ${ }^{41}$. However, the fact that silica nanofibers have a high surface area and also offer a high density of

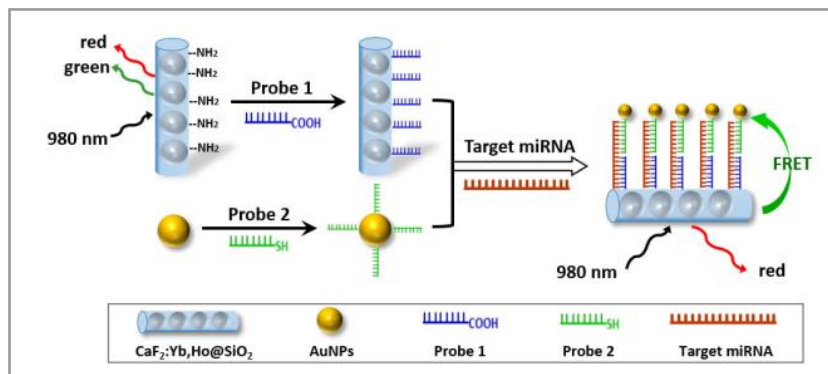

Figure 1 Schematic illustration for the synthesis of miRNA nanosensor based on $\mathrm{CaF}_{2}: \mathrm{Yb}, \mathrm{Ho} @ \mathrm{SiO}_{2}$ nanofibers and AuNPs.

Table 1 Sequences of the oligonucleotides.

\begin{tabular}{|c|c|}
\hline Primer Name & Sequence $\left(5^{\prime}\right.$ to $\left.3^{\prime}\right)$ \\
\hline $\begin{array}{l}\text { miRNA-capturing oligonucleotide } 1 \\
\text { (Probe 1) }\end{array}$ & 5'-COOH AAAAGCCAATATTTC-3' \\
\hline $\begin{array}{c}\text { miRNA-capturing oligonucleotide } 2 \\
\text { (Probe 2) }\end{array}$ & 5'-TGTGCTGCTAAAAAA SH-3' \\
\hline miR-195 (target miRNA) & 5'-UAGCAGCACAGAAAUAUUGGC-3' \\
\hline
\end{tabular}

$\mathrm{OH}$ groups on their surface means that they have the capacity to bind high numbers of DNA probes along their fiber surfaces and thereby offer the potential to facilitate miRNA detection. The processing properties of the nanofibers means that they can be processed to form a membrane and hence offer high levels of ease of handling.

Therefore, in order to develop a practical and functional biosensor, in this study, $\mathrm{Yb}$ and $\mathrm{Ho}$ co-doped $\mathrm{CaF}_{2}\left(\mathrm{CaF}_{2}: \mathrm{Yb}, \mathrm{Ho}\right)$ nanoparticles were synthesized using a hydrothermal process and were incorporated into electrospun $\mathrm{SiO}_{2}$ nanofibers $\left(\mathrm{CaF}_{2}: \mathrm{Yb}, \mathrm{Ho} @ \mathrm{SiO}_{2}\right)$ (Figure 1).

Two complementary miRNA-capturing oligonucleotides were selected to bind to two either end of the same miRNA target molecule. The $\mathrm{CaF}_{2}: \mathrm{Yb}, \mathrm{Ho} @ \mathrm{SiO}_{2}$ nanofibers were modified with amino groups to interact with a carboxyl group-functionalized miRNA-capturing oligonucleotide (Probe 1). Gold nanoparticles were conjugated with a thiol-modified miRNA-capturing oligonucleotide (Probe 2). When miRNA-195 was added into the system, it was therefore captured by the two different oligonucleotides and a sandwich-like complex was formed, as shown in Figure 1. Via this sandwich-type hybridization, the process led to AuNPs and $\mathrm{CaF}_{2}: \mathrm{Yb}$, $\mathrm{Ho} @ \mathrm{SiO}_{2}$ nanofibers being brought sufficiently close together to trigger the FRET effect, and the green emission of $\mathrm{CaF}_{2}: \mathrm{Yb}, \mathrm{Ho} @ \mathrm{SiO}_{2}$ nanofibers was absorbed by the AuNPs. By measuring the change in the fluorescence properties under $980 \mathrm{~nm}$ irradiation, a quantitative measurement of the target miRNA can be obtained.

\section{Results and discussion}

\section{1 $\mathrm{CaF}_{2}: \mathrm{Yb}$,Ho nanoparticles}

Scanning electron microscopy (SEM) indicated that the $\mathrm{CaF}_{2}: \mathrm{Yb}$, Ho nanoparticles synthesized hydrothermally at $180^{\circ} \mathrm{C}$ were spheroidal in morphology with a relatively monodisperse particle size of approximately $320 \mathrm{~nm}$ (Figure 2a). Figure S1 shows the particle diameter distribution. Transmission electron microscopy (TEM) revealed that the spheroidal nanoparticles were composed of aggregates of primary crystallites (Figure 2b). Lattice imaging using HRTEM shows clear lattice fringes indicating that the nanoparticles were highly crystalline (Figure 2c). Interplanar spacings of $0.276 \mathrm{~nm}$ and $0.310 \mathrm{~nm}$ were measured in two adjacent crystals and these dimensions correspond to the (200) and (111) planes of $\mathrm{CaF}_{2}$ respectively (JCPDS No. 35-0816). The XRD pattern for the $\mathrm{CaF}_{2}: \mathrm{Yb}$, Ho nanoparticles shows that all of the diffraction peaks matched well with the standard pattern for cubic $\mathrm{CaF}_{2}$ (JCPDS No. 35-0816) (Figure 3d). No obvious impurity peaks were observed, suggesting that the $\mathrm{Yb}^{3+}$ and $\mathrm{Ho}^{3+}$ ions were successfully incorporated into $\mathrm{CaF}_{2}$ lattice. After sintering at
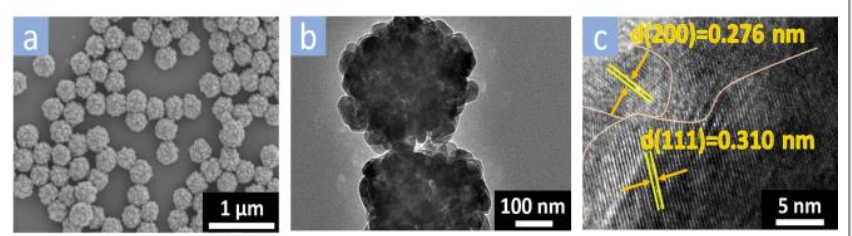

Figure 2 (a) SEM (b) TEM and (c) HRTEM images of $\mathrm{CaF}_{2}: \mathrm{Yb}, \mathrm{Ho}$ nanoparticles produced using hydrothermal svnthesis at $180^{\circ} \mathrm{C}$. 

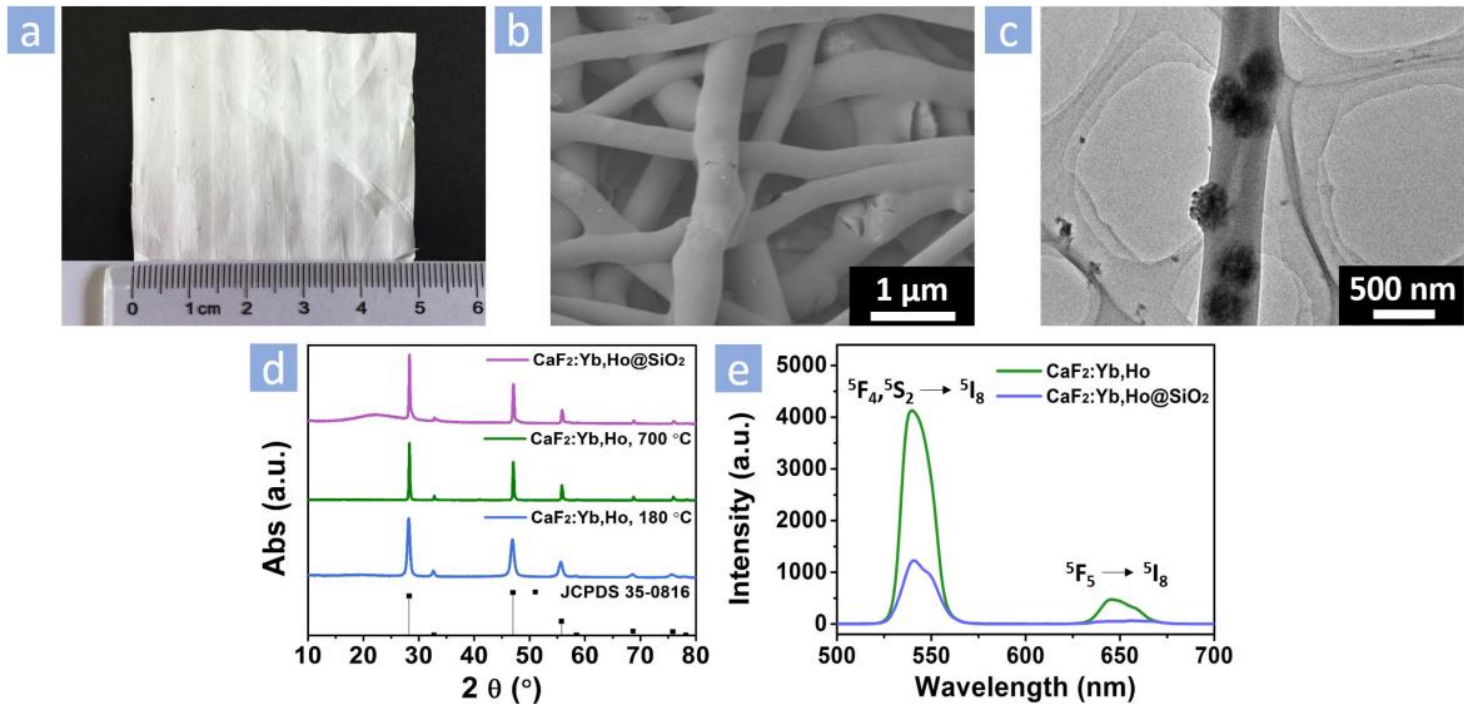

Figure 3 (a) Optical image of $\mathrm{CaF}_{2}: \mathrm{Yb}, \mathrm{Ho} @ \mathrm{SiO}_{2}$ nanofiber membrane. (b) SEM (c) TEM images of $\mathrm{CaF}_{2}: \mathrm{Yb}, \mathrm{Ho} @ \mathrm{SiO}_{2}$ nanofibers. (d) XRD patterns of $\mathrm{CaF}_{2}: \mathrm{Yb}$, Ho nanoparticles hydrothermally at $180{ }^{\circ} \mathrm{C}$ for $24 \mathrm{~h}$ (blue), $\mathrm{CaF}_{2}: \mathrm{Yb}, \mathrm{Ho}$ nanoparticles calcined at $700{ }^{\circ} \mathrm{C}$ for $4 \mathrm{~h}$ (green), $\mathrm{CaF}_{2}: \mathrm{Yb}, \mathrm{Ho} @ \mathrm{SiO}_{2}$ nanofibers (purple) and the standard profiles of $\mathrm{CaF}_{2}$ (JCPDS 35-0816) (black). (e) Upconversion photoluminescence spectra of $\mathrm{CaF}_{2}: \mathrm{Yb}$, Ho nanoparticles calcined at $700{ }^{\circ} \mathrm{C}$ for $4 \mathrm{~h}$ and $\mathrm{CaF}_{2}: \mathrm{Yb}_{1} \mathrm{Ho}_{\mathrm{S}} \mathrm{SiO}_{2}$ nanofibers.

$700{ }^{\circ} \mathrm{C}$, the nanoparticles had a similar morphology to the uncalcined material (Figure S2), but the sharper XRD peaks suggested that crystallinity had increased. Under irradiation at $980 \mathrm{~nm}$, the $\mathrm{CaF}_{2}: \mathrm{Yb}$, Ho nanoparticles exhibited two main upconversion emissions (Figure 3e). The green emission at about $541 \mathrm{~nm}$ is ascribed to the ${ }^{5} \mathrm{~F}_{4},{ }^{5} \mathrm{~S}_{2} \rightarrow{ }^{5} \mathrm{I}_{8}$ transition, and the relatively weak red emission at about $650 \mathrm{~nm}$ is assigned to a ${ }^{5} \mathrm{~F}_{5} \rightarrow{ }^{5} \mathrm{I}_{8}$ transition (Figure S3). ${ }^{42} \mathrm{Yb}^{3+}$ ions act as sensitizers in the system, which absorb infrared radiation $(980 \mathrm{~nm})$ and nonradiatively transfer their excitation to $\mathrm{Ho}^{3+}$ ions, thus populating not only the emitting levels but also the intermediate levels. ${ }^{43,} 44$

\subsection{Electrospinning of $\mathrm{CaF}_{2}: \mathrm{Yb}, \mathrm{Ho} @ \mathrm{SiO}_{2}$ nanofibers}

The $\mathrm{CaF}_{2}: \mathrm{Yb}, \mathrm{Ho} @ \mathrm{SiO}_{2}$ nanofibers were prepared by electrospinning. Figure $3 a$ shows an optical image of an electrospun $\mathrm{CaF}_{2}: \mathrm{Yb}, \mathrm{Ho} @ \mathrm{SiO}_{2}$ nanofiber membrane. Using SEM, the composite nanofibers were observed to have a smooth surface morphology and a diameter of approximately $490 \mathrm{~nm}$ (Figure 3b). TEM images revealed that the $\mathrm{CaF}_{2}: \mathrm{Yb}, \mathrm{Ho}$ nanoparticles were uniformly-distributed and along the length of the $\mathrm{SiO}_{2}$ nanofibers (Figure 3c). The presence of amorphous $\mathrm{SiO}_{2}$ was also confirmed from the XRD trace (Figure $3 \mathrm{~d}$ ), by the presence of a broad peak at $\sim 23^{\circ}$. The other sharp peaks, which are similar to the pattern of $\mathrm{CaF}_{2}: \mathrm{Yb}$, Ho nanoparticles, can be assigned to the particle phase in the nanofibers. In addition, the upconversion photoluminescence spectrum of $\mathrm{CaF}_{2}: \mathrm{Yb}, \mathrm{Ho} @ \mathrm{SiO}_{2}$ nanofibers under $980 \mathrm{~nm}$ irradiation was similar to the spectrum of the $\mathrm{CaF}_{2}: \mathrm{Yb}, \mathrm{Ho}$ nanoparticles, although emission intensity was weakened by $75 \%$ when the particles were incorporated into $\mathrm{SiO}_{2}$. This was due to the quenching effect of surface groups with high vibration frequency, such as - $\mathrm{OH}$ groups on the $\mathrm{SiO}_{2}$ nanofibers. Sol-gel $\mathrm{SiO}_{2}$ nanofibers have been investigated widely in nanomedicine due to their biocompatibility and ease of chemical decoration. The $\mathrm{CaF}_{2}: \mathrm{Yb}$, Ho particle embedded $\mathrm{SiO}_{2}$ nanofibers produced in this work, possess the advantages of $\mathrm{SiO}_{2}$ nanofibers while ensuring the upconversion photoluminescence features of $\mathrm{CaF}_{2}: \mathrm{Yb}, \mathrm{Ho}$ nanoparticles allowing the detection of miRNA via a FRET effect.

\subsection{Conjugation of Probe 1 with $\mathrm{CaF}_{2}: \mathrm{Yb}, \mathrm{Ho} @ \mathrm{SiO}_{2}$}

Prior to oligonucleotide conjugation, the $\mathrm{CaF}_{2}: \mathrm{Yb}, \mathrm{Ho} @ \mathrm{SiO}_{2}$ nanofibers were functionalized with amino groups using APTES. The $\mathrm{CaF}_{2}: \mathrm{Yb}, \mathrm{Ho} @ \mathrm{SiO}_{2}$ nanofibers were characterized before- and after amino modification using FTIR to demonstrate surface functionalization (Figure 4a). The FTIR spectrum of the $\mathrm{CaF}_{2}: \mathrm{Yb}, \mathrm{Ho} @ \mathrm{SiO}_{2}$ nanofibers reveals a typical $\mathrm{Si}-\mathrm{O}-\mathrm{Si}$ asymmetric stretching vibration at $1093 \mathrm{~cm}^{-1}$, Si-O-Si symmetric stretching vibration at $808 \mathrm{~cm}^{-1}$, and $\mathrm{Si}-\mathrm{O}-\mathrm{Si}$ bending vibration at $464 \mathrm{~cm}^{-1}$, which can be attributed to the $\mathrm{SiO}_{2}$ matrix. After amino functionalization, a new peak at $1560 \mathrm{~cm}^{-1}$ appeared, which can be assigned to $\mathrm{N}-\mathrm{H}$ stretching. The functionalization was also verified by studying changes in the zeta potential at various stages in the production process. For unfunctionalized $\mathrm{CaF}_{2}: \mathrm{Yb}, \mathrm{Ho} @ \mathrm{SiO}_{2}$ nanofibers, the zeta potential is $-13 \mathrm{mV}$ due to the abundance of $\mathrm{Si}-\mathrm{OH}$ groups on

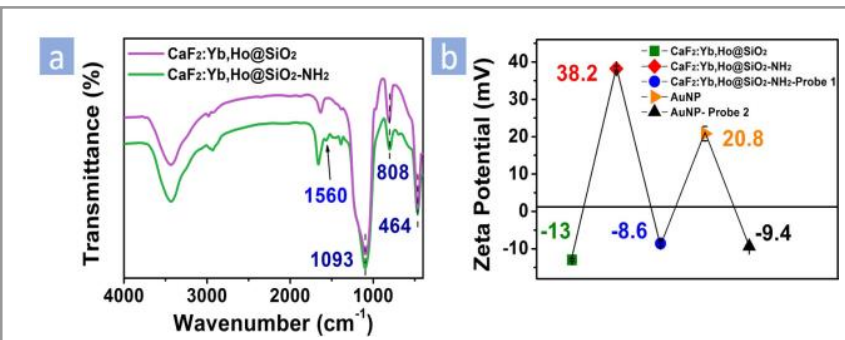

Figure 4 (a) FTIR spectra $\mathrm{CaF}_{2}: \mathrm{Yb}, \mathrm{Ho} @ \mathrm{SiO}_{2}$ nanofibers before and after amino modification. (b) Zeta potentials of $\mathrm{CaF}_{2}: \mathrm{Yb}, \mathrm{Ho} @ \mathrm{SiO}_{2}$ nanofibers, $\mathrm{CaF}_{2}: \mathrm{Yb}, \mathrm{Ho} @ \mathrm{SiO}_{2}-\mathrm{NH}_{2}$ nanofibers, $\mathrm{CaF}_{2}: \mathrm{Yb}, \mathrm{Ho} @ \mathrm{SiO}_{2}$-Probe 1, AuNPs, and Probe 2conjugated AuNPs. 

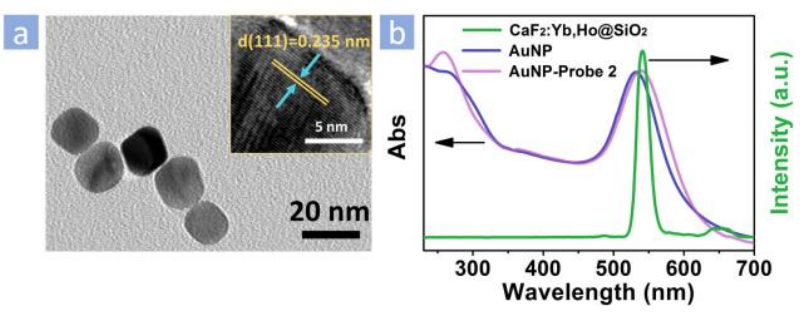

Figure 5 (a) SEM and (inset) TEM images of AuNPs; (b) UV-vis absorption of AuNPs and AuNP- Probe 2, and UCPL spectra of $\mathrm{CaF}_{2}: \mathrm{Yb}, \mathrm{Ho} @ \mathrm{SiO}_{2}$ nanofibers.

the surface (Figure 4b). After amino functionalization, the surface charge was reversed to $+38.2 \mathrm{mV}$. These data indicate the successful amino modification of the $\mathrm{CaF}_{2}: \mathrm{Yb}, \mathrm{Ho} @ \mathrm{SiO}_{2}$ nanofibers to form $\mathrm{CaF}_{2}: \mathrm{Yb}, \mathrm{Ho} @ \mathrm{SiO}_{2}-\mathrm{NH}_{2}$.

Subsequently, a carboxyl group-modified probe (Probe 1) was covalently grafted onto the $\mathrm{CaF}_{2}: \mathrm{Yb}, \mathrm{Ho} @ \mathrm{SiO}_{2}-\mathrm{NH}_{2}$ nanofibers via an amide reaction. The UV-vis spectrum of Probe 1 shows a typical absorption peak around $260 \mathrm{~nm}$ (Figure S4). $\mathrm{CaF}_{2}: \mathrm{Yb}, \mathrm{Ho} @ \mathrm{SiO}_{2}-\mathrm{NH}_{2}$ nanofibers exhibited a 'plain' absorption spectrum, implying that the nanofibers unconjugated with Probe 1 merely absorb light from $\lambda=230$ to $300 \mathrm{~nm}$. However, in the case of the Probe 1-conjugated $\mathrm{CaF}_{2}: \mathrm{Yb}, \mathrm{Ho} @ \mathrm{SiO}_{2}-\mathrm{NH}_{2}$ nanofibers $\left(\mathrm{CaF}_{2}: \mathrm{Yb}, \mathrm{Ho} @ \mathrm{SiO}_{2}-\right.$ Probe 1$)$, successful conjugation was confirmed by a new broad peak in the UV-vis absorption spectrum at $\lambda=265 \mathrm{~nm}$, and this was further supported by the negative zeta potential of $\mathrm{CaF}_{2}: \mathrm{Yb}, \mathrm{Ho} @ \mathrm{SiO}_{2}-$ Probe 1 (-8.6 mV) resulting from presence of the negatively charged oligonucleotide strand.

\subsection{Conjugation of Probe 2 with AuNPs}

The AuNPs were synthesized by a seed-mediated method. ${ }^{45}$ As shown in Figure 5a, the synthesized AuNPs had an average diameter of $16.3 \pm 2.1 \mathrm{~nm}$. The lattice $\mathrm{d}$-spacing calculated from the HRTEM image is $0.235 \mathrm{~nm}$, corresponding to the (111) crystal plane of gold (JCPDS No. 04-0784).

In our design, a thiol group-modified probe (Probe 2) was immobilized on the surface of the AuNPs via an Au-S bond. The zeta potential of the pure AuNPs was $+20.8 \mathrm{mV}$ due to the CTAB layer, but this reversed to $-9.4 \mathrm{mV}$ after the formation of the AuNP-Probe 2 conjugation (Figure $4 b$ ). This surface charge reversal appeared to confirm that functionalization achieved as intended. This result is further supported by UV-vis
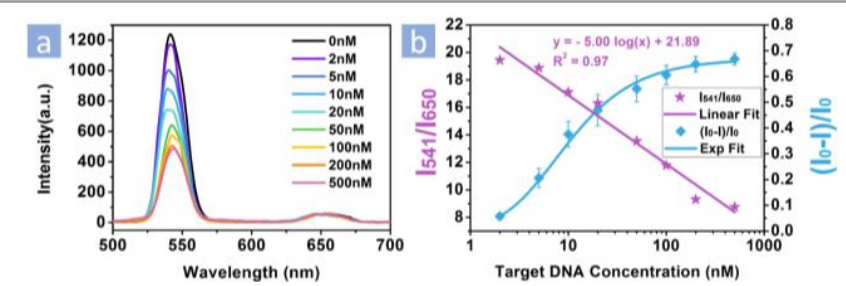

Figure 6 (a) UCPL spectra of nanofibers at different concentrations of target miRNA. (b) Linear relationship between the intensity ratio $I_{541} / I_{650}$ and the concentration of target miRNA (purple); Exponential relationship between the quenching UCPL intensity at $541 \mathrm{~nm}$ and the concentration of target miRNA (blue)
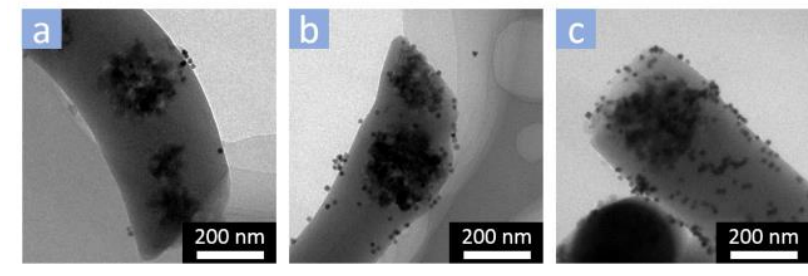

Figure 7 TEM images of AuNPs- Probe 2 conjugated with $\mathrm{CaF}_{2}: \mathrm{Yb}, \mathrm{Ho} @ \mathrm{SiO}_{2}$ upon different concentrations of target miRNA: (a) 0, (b) $50 \mathrm{nM}$, (c) $500 \mathrm{nM}$.

absorption measurements (Figure 5b). The absorption peak for the AuNPs was found to be located at $535 \mathrm{~nm}$ and the small absorption peak at around $300 \mathrm{~nm}$ was due to the CTAB coating. After oligonucleotide conjugation, AuNP-Probe 2 spectrum showed clear evidence of absorbance at $260 \mathrm{~nm}$, confirming the successful immobilization of Probe 2 on the AuNPs.

A key result is that the UV-vis absorption spectrum of AuNPsProbe 2 overlaps exactly with the strong green emission of the $\mathrm{CaF}_{2}: \mathrm{Yb}$,Ho@SiO ${ }_{2}$ nanofibers. This is essential for the FRET effect to occur.

\subsection{Detection of miRNA}

The conjugation results presented above, show that it is possible to achieve a FRET effect between the $\mathrm{CaF}_{2}: \mathrm{Yb}, \mathrm{Ho} @ \mathrm{SiO}_{2}$ - Probe 1 (energy donor) and AuNP- Probe 2 (energy acceptor). In addition, the green emission is much stronger as compared with the red emission, which is ideal for application as an energy donor in FRET-based analysis. A membrane made of Probe 1-containing $\mathrm{CaF}_{2}: \mathrm{Yb}, \mathrm{Ho} @ \mathrm{SiO}_{2}$ nanofibers and Probe 2-conjugated AuNPs was placed in a 20 $\mathrm{mL}$ glass bottle containing $2 \mathrm{~mL}$ de-ionised water. The target miRNA was then added and co-hybridization occurred between the target miRNA and the oligonucleotides. The nanofibers and AuNPs were consequently brought into close proximity, triggering the FRET effect. As shown in Figure 6a, the intensity of green emission at 541 $\mathrm{nm}$ was quenched significantly, whereas the red emission at 650 $\mathrm{nm}$ remained unchanged, indicating energy transfer from the green emission of photoluminescent nanofibers to AuNPs. The green emission intensity decreased by about $60 \%$ when the concentration of target miRNA was $500 \mathrm{nM}$. This was due to strong absorption by the AuNP-Probe 2 combination at $541 \mathrm{~nm}$ and very low absorption at $650 \mathrm{~nm}$. As the concentration of target miRNA was increased, the intensity of green emission decreased. Generally, FRET will occur when the distance between donors and acceptors is below $10 \mathrm{~nm} \cdot{ }^{46-48} \mathrm{In}$ this work, it is proposed that, with increasing miRNA concentration, increasing numbers of AuNPs were brought into close proximity and conjugated with the nanofibers to provide a suitable acceptor-to-donor distance for FRET to occur and this was characterized by quenching of the green emission (Figure 7).

To explore the quenching efficiency of the FRET system, different miRNA concentrations, ranging from $2 \mathrm{nM}-500 \mathrm{nM}$, were tested. Figure $6 b$ shows the relationship between the quenching of 
emission intensity $\Delta I\left(\Delta I=\left(I_{0}-I\right) / I_{0}\right)$ and the concentration of target miRNA (where $I_{0}$ and $I$ represent the green emission intensity of $\mathrm{CaF}_{2}: \mathrm{Yb}, \mathrm{Ho} @ \mathrm{SiO}_{2}$ nanofibers in the absence and presence of different concentrations of target miRNA, respectively). The quenching efficiency increased with increasing target miRNA concentration and the intensity ratio $\left(I_{541} / I_{650}\right)$ was found to vary linearly with the concentration of target miRNA. At a miRNA concentration of $500 \mathrm{nM}$, the quenching efficiency reached a value of $67 \%$.

\section{Conclusions}

In summary, a novel UCPL-based FRET biosensor utilizing amino-modified $\mathrm{CaF}_{2}: \mathrm{Yb}$, $\mathrm{Ho} @ \mathrm{SiO}_{2}$ nanofibers and AuNPs was developed for miRNA-195 detection. The sandwich structure formed as a result of co-hybridization of target miRNA via the action of oligonucleotides allowed the nanofibers and AuNPs to be brought into sufficiently close proximity to trigger a FRET effect. The intensity ratio of green to red emission, $I_{541} / I_{650}$, varied linearly with miRNA concentration, allowing the result to be utilized as a standard curve for quantitative determination target miRNA. This work demonstrates the feasibility of using co-conjugated probes, AuNPs and nanofibers that can be processed to form a membrane. Further work will investigate the use of multiple combinations of upconversion photoluminescent particle-impregnated nanofibers for the simultaneous detection of several biomarkers, relevant to early stage cancer diagnosis.

\section{Materials and Methods}

\subsection{Synthesis of $\mathrm{CaF}_{2}: \mathrm{Yb}$,Ho Nanoparticles}

$\mathrm{CaF}_{2}: \mathrm{Yb}$, Ho nanoparticles were prepared using a hydrothermal process based on a method reported by Deng et al. (2015). ${ }^{49}$ Calcium nitrate tetrahydrate $\left(\mathrm{Ca}\left(\mathrm{NO}_{3}\right)_{2} \cdot 4 \mathrm{H}_{2} \mathrm{O}, 1 \mathrm{mmol}\right.$, A.R., Sinopharm Chemical, China), ytterbium nitrate pentahydrate $\left(\mathrm{Yb}\left(\mathrm{NO}_{3}\right)_{3} \cdot 5 \mathrm{H}_{2} \mathrm{O}, 0.2125 \mathrm{mmol}, 99.9 \%\right.$, Sigma-Aldrich), holmium nitrate pentahydrate $\left(\mathrm{Ho}\left(\mathrm{NO}_{3}\right)_{3} \cdot 5 \mathrm{H}_{2} \mathrm{O}, 0.0375 \mathrm{mmol}, 99.9 \%\right.$, SigmaAldrich), trisodium citrate ( $\mathrm{Cit}^{3-}, 2 \mathrm{mmol}, 99.0 \%$, Aladdin) and sodium fluoroborate $\left(\mathrm{NaBF}_{4}, 2 \mathrm{mmol}, 99.99 \%\right.$, Aladdin) were dissolved in $40 \mathrm{~mL}$ of deionized water and ammonia solution was added to maintain the $\mathrm{pH}$ at 7.0. The solution was transferred into a $50 \mathrm{ml}$ stainless-steel Teflon autoclave and maintained at $180{ }^{\circ} \mathrm{C}$ for $24 \mathrm{~h}$. The precipitate obtained was collected by centrifugation, washed and dried at $80{ }^{\circ} \mathrm{C}$ for $24 \mathrm{~h}$ to obtain $\mathrm{CaF}_{2}: \mathrm{Yb}, \mathrm{Ho}$ nanoparticles. The $\mathrm{CaF}_{2}: \mathrm{Yb}, \mathrm{Ho}$ nanoparticles obtained were then calcined at $700{ }^{\circ} \mathrm{C}$ for $4 \mathrm{~h}$.

\subsection{Fabrication of $\mathrm{CaF}_{2}: \mathrm{Yb}, \mathrm{Ho} @ \mathrm{SiO}_{2}$ Nanofibers}

$1.67 \mathrm{~g}$ of tetraethyl orthosilicate (TEOS, A.R., Sinopharm Chemical, China), $200 \mu \mathrm{L}$ of acetic acid (A.R., Sinopharm Chemical, China), 600 $\mu \mathrm{L}$ of deionized water and $10 \mathrm{~mL}$ of ethanol (99.9 vol \%, Sinopharm Chemical, China) were mixed by stirring for $1.5 \mathrm{~h}$. Then $1.5 \mathrm{~mL}$ of N,N-dimethylformamide (DMF, A.R., Sinopharm Chemical, China), $1.2 \mathrm{~g}$ of polyvinylpyrrolidone (PVP, Mw =1 300 000, Aladdin), and 50 $\mathrm{mg}$ of the calcined $\mathrm{CaF}_{2}: \mathrm{Yb}$, Ho nanoparticles were added and stirred for $2 \mathrm{~h}$ to obtain the electrospinning precursor.
For the electrospinning process, the precursor solution was transferred into a single nozzle electrospinning setup. The flow rate was set at $1.5 \mathrm{~mL} / \mathrm{h}$. The distance and the high voltage between the needle tip and the collector were set at $15 \mathrm{~cm}$ and $8-11 \mathrm{kV}$, respectively. The as-spun composite nanofibers were dried at $80{ }^{\circ} \mathrm{C}$ overnight and calcined at $600{ }^{\circ} \mathrm{C}$ for $4 \mathrm{~h}$.

\subsection{Functionalization of $\mathrm{CaF}_{2}: \mathrm{Yb}, \mathrm{Ho} @ \mathrm{SiO}_{2}$ Nanofibers with Amino Groups}

$100 \mathrm{mg}$ of $\mathrm{CaF}_{2}: \mathrm{Yb}, \mathrm{Ho} @ \mathrm{SiO}_{2}$ nanofibers and $0.8 \mathrm{~mL}$ of $3-$ aminopropyl-triethoxysilane (APTES, $99 \%$, Macklin) were dispersed in $40 \mathrm{~mL}$ of DMF and stirred at $80^{\circ} \mathrm{C}$ for $24 \mathrm{~h}$. Then the nanofibers were centrifuged and washed three times with DMF to obtain amino modified $\mathrm{CaF}_{2}: \mathrm{Yb}, \mathrm{Ho} @ \mathrm{SiO}_{2}$ nanofibers $\left(\mathrm{CaF}_{2}: \mathrm{Yb}, \mathrm{Ho} @ \mathrm{SiO}_{2-}\right.$ $\mathrm{NH}_{2}$ ).

\subsection{Conjugation of Probe 1 with $\mathrm{CaF}_{2}: \mathrm{Yb}, \mathrm{Ho} @ \mathrm{SiO}_{2}$ Nanofibers}

In order to covalently conjugate Probe 1 to $\mathrm{CaF}_{2}: \mathrm{Yb}, \mathrm{Ho} @ \mathrm{SiO}_{2}-\mathrm{NH}_{2}$ nanofibers, carboxyl group-modified miRNA-capturing oligonucleotide 1 (Probe 1, 5'-COOH AAAAAGCCAATATTTC-3', 25 $\mu \mathrm{L}, 100 \mu \mathrm{M}$, Sangon Biotechnology Co., Ltd. Shanghai, China), Nhydroxy-succinimide (NHS, $200 \mu \mathrm{L}, 2 \mathrm{mg} / \mathrm{mL}, 97.0 \sim 102.0 \%$, Sinopharm Chemical, China) and 1-ethyl-3-(3-dimethylaminopropy) carbodiimide (EDC, $400 \mu \mathrm{L}, 2 \mathrm{mg} / \mathrm{mL}, 98.0 \%$, Aladdin) were incubated in $2.5 \mathrm{~mL}$ of ultrapure water at $37{ }^{\circ} \mathrm{C}$ for $1 \mathrm{~h}$. Then, $5 \mathrm{mg}$ of $\mathrm{CaF}_{2}: \mathrm{Yb}, \mathrm{Ho} @ \mathrm{SiO}_{2}-\mathrm{NH}_{2}$ nanofibers were added into the solution and reacted at $37{ }^{\circ} \mathrm{C}$ for $24 \mathrm{~h}$. The conjugates formed were centrifuged with water three times and then redispersed in $800 \mu \mathrm{L}$ of water.

\subsection{Synthesis of Gold Nanoparticles}

\subsubsection{Seed Solution}

The gold nanoparticles (AuNPs) were fabricated according to a modified version of the well-established seed-mediated growth method. ${ }^{45}$ Briefly, CTAB aqueous solution $(5 \mathrm{~mL}, 0.2 \mathrm{M}$, A.R., Sinopharm Chemical, China) was mixed with $\mathrm{HAuCl}_{4}(5 \mathrm{~mL}, 0.5 \mathrm{mM}$, A.R. Sinopharm Chemical, China) and ice-cold $\mathrm{NaBH}_{4}(0.6 \mathrm{~mL}, 0.01$ $M, 96 \%$, Sinopharm Chemical, China) under vigorous stirring for 2 min. Then the brownish-yellow seed solution was aged at room temperature for $3 \mathrm{~h}$ before use.

\subsubsection{Growth Solution}

The growth solution was made from solutions of CTAB (0.2 M, 6 $\mathrm{mL}), \mathrm{HAuCl}_{4}(0.5 \mathrm{mM}, 6 \mathrm{~mL})$, and ascorbic acid $(0.1 \mathrm{M}, 4.5 \mathrm{~mL}, 99.7$ $\%$, Sinopharm Chemical, China). The gold seed solution $(0.3 \mathrm{~mL})$ was then injected into the growth solution and the mixture was stirred for $1 \mathrm{~h}$ and left undisturbed overnight. The AuNPs obtained were centrifuged to remove excess $C T A B$ and ascorbic acid, re-suspended and concentrated 50 -fold in $0.005 \mathrm{M} \mathrm{CTAB}$ solution for the following experiments.

\subsection{Synthesis of AuNP-Probe 2 Conjugation}

The modification of AuNPs was conducted following a modified version of protocols reported previously by Yi et al., Xu et al., Liu et al. and Zhang et al. ${ }^{50-53}$ A volume of $60 \mu \mathrm{L}, 100 \mathrm{mM}$ thiol-modified miRNA-capturing oligonucleotide 2 (Probe 2, 5' TGTGCTGCTAAAAAA SH-3', Sangon Biotechnology Co., Ltd. Shanghai, China) was pipetted into a micro centrifuge tube. Then 1 
$\mu \mathrm{L}$ of $10 \mathrm{mM}$ fresh Tris-(2-carboxyethyl) phosphine hydrochloride (TCEP, $\geq 98 \%$, Sigma-Aldrich.) was added to the tube to activate the thiol-modified Probe 2. The sample was incubated at room temperature for $1 \mathrm{~h}$, before $300 \mu \mathrm{L}$ of the prepared AuNP solution into the tube. The mixture was then allowed to react at $25{ }^{\circ} \mathrm{C}$ for at least $16 \mathrm{~h}$ in the dark with gentle shaking. After incubation, the conjugate was collected after three consecutive purification cycles comprising centrifugation for $10 \mathrm{~min}$ at $6000 \mathrm{rpm}$ and redispersed in $0.005 \mathrm{M} \mathrm{CTAB}$ buffer. The conjugate was stored at $4{ }^{\circ} \mathrm{C}$.

\subsection{Detection of Target MiRNA Based on the FRET System}

$800 \mu \mathrm{l}$ of $\mathrm{CaF}_{2}: \mathrm{Yb}, \mathrm{Ho} @ \mathrm{SiO}_{2}-\mathrm{NH}_{2}-$ Probe 1 solution, $800 \mu \mathrm{l}$ of AuNPProbe 2, and $400 \mu \mathrm{L}$ of target miRNA (miRNA 195, UAGCAGCACAGAAAUAUUGGC, Sangon Biotechnology Co., Ltd. Shanghai, China), with concentrations ranging from $2 \mathrm{nM}$ to 500 $\mathrm{nM}$, were mixed and incubated at $25^{\circ} \mathrm{C}$ for $1 \mathrm{~h}$. The mixture was centrifuged, washed twice with water and re-suspended in $2 \mathrm{~mL}$ of water.

\subsection{Characterization}

The morphologies and microstructures of the $\mathrm{CaF}_{2}: \mathrm{Yb}$, Ho nanoparticles, $\mathrm{CaF}_{2}: \mathrm{Yb}, \mathrm{Ho} @ \mathrm{SiO}_{2}$ nanofibers, AuNPs, and AuNPs conjugated $\mathrm{CaF}_{2}: \mathrm{Yb}, \mathrm{Ho} @ \mathrm{SiO}_{2}$ nanofibers were characterized using field emission scanning electron microscopy (FESEM, SU-70, Hitachi) and high-resolution transmission electron microscopy (HRTEM, Tecnai F20, FEI). The XRD patterns were recorded using a RIGAKU D/MAX 2550/PC multi crystal diffractometer. FTIR spectra were measured on a Perkin-Elmer 580B (Tensor 27, Bruker) infrared spectrophotometer using the $\mathrm{KBr}$ pellet technique. UV-vis spectroscopy measurements were performed on TU-1810 UV-vis spectrophotometer. Measurements of zeta potential were collected on a zetasizer (Zetasizer 3000 HSA, Malvern). Diluted aqueous solution of samples were performed in quintuplicates. The UCPL spectra were obtained under the excitation of a continuous laser with a wavelength of $980 \mathrm{~nm}$ from a fluorescence spectrophotometer (PL, FLSP920, Edinburgh). The diameter distributions were obtained by stochastically choosing and measuring of fifty fibers from SEM images.

\section{Acknowledgements}

This work was financially supported by the National Nature Science Foundation of China (51232006 and 51672247), the '111' Program funded by Education Ministry of China and State Administration of Foreign Experts Affairs (B16043), the Major State Research Program of China (2016YFC1101900), and the Nature Science Foundation of Zhejiang Province (LY15E020005).

\section{Notes and references}

1. L. A. Torre, F. Bray, R. L. Siegel, J. Ferlay, J. Lortet-Tieulent and A. Jemal, CA-Cancer J. Clin., 2015, 65, 87-108.

2. D. P. Bartel, Cell, 2004, 116, 281-297.

3. N. Bushati and S. M. Cohen, Annu. Rev. Cell Dev. Biol., 2007, 23, 175-205.

4. W. Liu, S.-Y. Mao and W.-Y. Zhu, World journal of gastroenterology, 2007, 13, 497.
5. R. Garzon, G. A. Calin and C. M. Croce, Annu. Rev. Med., 2009, 60, 167-179.

6. X. Chen, Y. Ba, L. Ma, X. Cai, Y. Yin, K. Wang, J. Guo, Y. Zhang, J. Chen, X. Guo, Q. Li, X. Li, W. Wang, Y. Zhang, J. Wang, X. Jiang, Y. Xiang, C. Xu, P. Zheng, J. Zhang, R. Li, H. Zhang, X. Shang, T. Gong, G. Ning, J. Wang, K. Zen, J. Zhang and C.-Y. Zhang, Cell Res., 2008, 18, 997-1006.

7. J. Li, S. Tan, R. Kooger, C. Zhang and Y. Zhang, Chem. Soc. Rev., 2014, 43, 506-517.

8. L. Liu, L. Chen, Y. Xu, R. Li and X. Du, Biochem. Biophys. Res. Commun., 2010, 400, 236-240.

9. H. M. Heneghan, N. Miller, A. J. Lowery, K. J. Sweeney, J. Newell and M. J. Kerin, Annals of Surgery, 2010, 251, 499505.

10. H. M. Heneghan, N. Miller, R. Kelly, J. Newell and M. J. Kerin, The Oncologist, 2010, 15, 673-682.

11. P. S. Mitchell, R. K. Parkin, E. M. Kroh, B. R. Fritz, S. K. Wyman, E. L. Pogosova-Agadjanyan, A. Peterson, J. Noteboom, K. C. O'Briant, A. Allen, D. W. Lin, N. Urban, C. W. Drescher, B. S. Knudsen, D. L. Stirewalt, R. Gentleman, R. L. Vessella, P. S. Nelson, D. B. Martin and M. Tewari, Proceedings of the National Academy of Sciences, 2008, 105, 10513-10518.

12. K. E. Resnick, H. Alder, J. P. Hagan, D. L. Richardson, C. M. Croce and D. E. Cohn, Gynecologic Oncology, 2009, 112, 55-59.

13. M. Lin, P. Song, G. Zhou, X. Zuo, A. Aldalbahi, X. Lou, J. Shi and C. Fan, Nat. Protocols, 2016, 11, 1244-1263.

14. S. Husale, H. H. J. Persson and O. Sahin, Nature, 2009, 462, 1075-1078.

15. Q. Wang, R. Liu, X. Yang, K. Wang, J. Zhu, L. He and Q. Li, Sensors Actuators B: Chem., 2016, 223, 613-620.

16. Z. Jin, D. Geißler, X. Qiu, K. D. Wegner and N. Hildebrandt, Angew. Chem. Int. Ed., 2015, 54, 10024-10029.

17. Y. Liu, M. Wei, Y. Li, A. Liu, W. Wei, Y. Zhang and S. Liu, Anal. Chem., 2017, 89, 3430-3436.

18. Q. Wang, B.-C. Yin and B.-C. Ye, Biosens. Bioelectron., 2016, 80, 366-372.

19. J. Shi, C. Chan, Y. Pang, W. Ye, F. Tian, J. Lyu, Y. Zhang and M. Yang, Biosens. Bioelectron., 2015, 67, 595-600.

20. L. Wang, J. Liu, Y. Dai, Q. Yang, Y. Zhang, P. Yang, Z. Cheng, H. Lian, C. Li, Z. Hou, P. a. Ma and J. Lin, Langmuir, 2014, 30, 13042-13051.

21. Y. Li, Y. Zhou, T. Gu, G. Wang, Z. Ren, W. Weng, X. Li, G. Han and C. Mao, Particle \& Particle Systems Characterization, 2016, 33, 896-905.

22. Y. Fu, X. Li, C. Sun, Z. Ren, W. Weng, C. Mao and G. Han, ACS Appl. Mater. Interfaces, 2015, 7, 25514-25521.

23. H. Liu, Y. Fu, Y. Li, Z. Ren, X. Li, G. Han and C. Mao, Langmuir, 2016, 32, 9083-9090.

24. Y. Fu, C. Fang, Z. Ren, G. Xu, X. Li and G. Han, Chem-Eur J, 2017, 23, 2423-2431.

25. H. J. M. A. A. Zijlmans, J. Bonnet, J. Burton, K. Kardos, T. Vail, R. S. Niedbala and H. J. Tanke, Anal. Biochem., 1999, 267, 30-36.

26. S. Wu, G. Han, D. J. Milliron, S. Aloni, V. Altoe, D. V. Talapin, B. E. Cohen and P. J. Schuck, Proc. Natl. Acad. Sci. U.S.A., 2009, 106, 10917-10921.

27. H. Du, J. Yu, D. Guo, W. Yang, J. Wang and B. Zhang, Langmuir, 2016, 32, 1155-1165.

B. Liu, C. Li, B. Xing, P. Yang and J. Lin, J. Mater. Chem. B, 2016, 4, 4884-4894. 
29. Q. Han, Z. Dong, X. Tang, L. Wang, Z. Ju and W. Liu, J. Mater. Chem. B, 2017, 5, 167-172.

30. Y. Dai, H. Bi, X. Deng, C. Li, F. He, P. a. Ma, P. Yang and J. Lin, J. Mater. Chem. B, 2017, 5, 2086-2095.

31. Y. Li, Y. Zhou, X. Li, J. Sun, Z. Ren, W. Wen, X. Yang and G. Han, RSC Advances, 2016, 6, 38365-38370.

32. N.-N. Dong, M. Pedroni, F. Piccinelli, G. Conti, A. Sbarbati, J. E. Ramírez-Hernández, L. M. Maestro, M. C. Iglesias-de la Cruz, F. Sanz-Rodriguez, A. Juarranz, F. Chen, F. Vetrone, J. A. Capobianco, J. G. Solé, M. Bettinelli, D. Jaque and A. Speghini, ACS Nano, 2011, 5, 8665-8671.

33. B. Zhou, L. Tao, Y. H. Tsang and W. Jin, J. Mater. Chem. C, 2013, 1, 4313-4318.

34. W. Zheng, S. Zhou, Z. Chen, P. Hu, Y. Liu, D. Tu, H. Zhu, R. Li, M. Huang and X. Chen, Angew. Chem., 2013, 125, 6803-6808.

35. F. Perche, Y. Yi, L. Hespel, P. Mi, A. Dirisala, H. Cabral, K. Miyata and K. Kataoka, Biomaterials, 2016, 90, 62-71.

36. W. Hou, P. Wei, L. Kong, R. Guo, S. Wang and X. Shi, J. Mater. Chem. B, 2016, 4, 2933-2943.

37. K. A. Fitzgerald, K. Rahme, J. Guo, J. D. Holmes and C. M. O'Driscoll, J. Mater. Chem. B, 2016, 4, 2242-2252.

38. M. Wang, W. Hou, C.-C. Mi, W.-X. Wang, Z.-R. Xu, H.-H. Teng, C.-B. Mao and S.-K. Xu, Anal. Chem., 2009, 81, 87838789.

39. J. G. Jesu Raj, M. Quintanilla, K. A. Mahmoud, A. Ng, F. Vetrone and M. Zourob, ACS Appl. Mater. Interfaces, 2015, 7, 18257-18265.

40. S. Wu, N. Duan, X. Li, G. Tan, X. Ma, Y. Xia, Z. Wang and H. Wang, Talanta, 2013, 116, 611-618.

41. Z. Xia, Y. Fu, T. Gu, Y. Li, H. Liu, Z. Ren, X. Li and G. Han, Materials \& Design, 2017, 119, 85-92.

42. F. He, P. Yang, D. Wang, C. Li, N. Niu, S. Gai and M. Zhang, Langmuir, 2011, 27, 5616-5623.

43. C. Ma, X. Xu, F. Wang, Z. Zhou, D. Liu, J. Zhao, M. Guan, C. I. Lang and D. Jin, Nano Lett., 2017, 17, 2858-2864.

44. B. Zhou, B. Shi, D. Jin and X. Liu, Nat Nano, 2015, 10, 924936.

45. R. Contreras-Cáceres, A. Sánchez-Iglesias, M. Karg, I. Pastoriza-Santos, J. Pérez-Juste, J. Pacifico, T. Hellweg, A. Fernández-Barbero and L. M. Liz-Marzán, Adv. Mater., 2008, 20, 1666-1670.

46. Q. Su, W. Feng, D. Yang and F. Li, Acc. Chem. Res., 2016.

47. V. Muhr, C. Würth, M. Kraft, M. Buchner, A. J. Baeumner, U. Resch-Genger and T. Hirsch, Anal. Chem., 2017, 89, 4868-4874.

48. Y. Fu, X. Chen, X. Mou, Z. Ren, X. Li and G. Han, ACS Biomater.-Sci. Eng., 2016, 2, 652-661.

49. X. Deng, Y. Dai, J. Liu, Y. Zhou, P. a. Ma, Z. Cheng, Y. Chen, K. Deng, X. Li, Z. Hou, C. Li and J. Lin, Biomaterials, 2015, 50, 154-163.

50. Y. Yi, H. Wang, X. Wang, Q. Liu, M. Ye and W. Tan, ACS Appl. Mater. Interfaces, 2017, 9, 5847-5854.

51. L. Xu, H. Kuang, C. Xu, W. Ma, L. Wang and N. A. Kotov, J. Am. Chem. Soc., 2012, 134, 1699-1709.

52. J. Liu and Y. Lu, Nat. Protocols, 2006, 1, 246-252.

53. J. Zhang, S. Song, L. Wang, D. Pan and C. Fan, Nat. Protocols, 2007, 2, 2888-2895. 